\title{
Public Health Awareness Building in the field of Safe Motherhood
}

\author{
Bhatta BN ${ }^{1}$ \\ ${ }^{1}$ Kathmandu, Nepal.
}

\section{ABSTRACT}

\begin{abstract}
Background: The study aims to explore the awareness level of people on safe motherhood in some selected districts and to compare the situation on the given issues among the selected districts.

Methods: A total of 400 sample households (HHs) were represented from the 20 wards from $10 \mathrm{VDCs}$ of four districts in the country during the fieldwork from April to August 2006. The sampled VDCs and wards were selected with the meeting of respective stakeholders from district to village levels respectively. A semi- structured questionnaire and ethnographic observation were administrated for garnering required data.

Results: Out of the total respondents, the awareness level in marital age has been slightly increased in sampled communities. 29\% marriages took place below the age of 18 years. 58.3\% reported they married at the age of 18 to 22 years followed by above 22 years (12.5\%). In case of cutting placenta, 58.9\% are found to use blades followed by sterilized blades (20\%) and others including sickle and knife (15\%). Among them, majority people still practised delivery at home rather than public health institutes. The study indicates that $80.5 \%$ population reported they managed home delivery followed by health institutes (18.3\%). Similarly, 30\% respondents expressed mothers- in- law assist during delivery. $69 \%$ informants reported that they milked colostrums to infant. Therefore, public health awareness program has to be arranged for the increase its level in some selected areas.

Conclusion: Safe motherhood is the significant component of reproductive health. Uterus prolapse in Nepal is the most complicated problem in this field. Despite the various efforts, public health awareness programs have to be arranged in the critical areas of reproductive health.

Key words: awareness, health education, public, safe motherhood
\end{abstract}

\section{INTRODUCTION}

The life expectancy is 63.3 years and Infant Mortality Rate has been 64 per 1000 live births in 2006. Maternal Mortality Rate, a key indicator of reproductive health care services has been decreased from 539 per 100000 live births in1996..$^{1-3}$ Complicated pregnancy and problem during childbirth are the major causes influencing to maternal health. The total numbers of MCHW and nurse/ ANW are 3190 and 11637 consecutively in the country during 2006. As subsistence economy, majority of people (65\%) are fully depend on agriculture with livestock. $31 \%$ populations are still below the poverty line. Such figure reveals that Nepal has to be made a significant effort for changing current socio- economic situation of the country. ${ }^{3-5}$

With education, training, empowerment and awareness through the effort of government, other stakeholders the situation at present has been gradually improving.

Correspondence: Badri Nath Bhatta, Kathmandu, Nepal. Phone: 9841847591, Email: badri_bhatta2003@yahoo.com 
Public Health Awareness Building in the field of Safe Motherhood

However, some of the maternal health related problems such as maternal mortality is still higher, uterus prolapse and other women related diseases are widely found in rural and distant areas of the country. During fieldwork, even Chhapmi, the adjoining VDC from ring road in Lalitpur District, most of the women of wards 1 and 6 complained that the complicated disease related to safe motherhood in this VDC is uterus prolapse. Experiences also showed that the avoidance of the three delays was imperative to achieve the goal of reducing maternal mortality. Three delays include delay in seeking care, delay in reaching care and delay in receiving care. In this context, the study attempts to explore the level of public awareness on safe motherhood in some selected districts of the country. ${ }^{4-7}$

\section{METHODS}

This was the field-based study of four districts representing from hill to Terai regions of the country. They are Sapatari, Dhanusa, Kavrepalanchock and Lalitpur Districts. The districts were selected based on the suggestion of NHRC. 20 wards from 10 VDCs of four districts were studied. The sampled VDCs and wards were selected with the meeting of respective stakeholders from district to village levels respectively. The fieldwork was carried out on April to August 2006. The total population during field visit was 2783 in the sample VDCs. As based on research design, two Districts from each Region were taken as sample where the sample of $80 \mathrm{HHs}$ from each hilly district and $120 \mathrm{HHs}$ from each Terai district were determined. In this case, the total sample of 400 questionnaires was calculated. Based on the limited time frame, certain budget along with approval of NHRC, the proportion of the VDCs differs from hill to Terai regions. For the collection of required first hand data, semi- structured survey questionnaire and ethnographic observation were administrated as research techniques. Secondary sources were also used for the discussion of this article. That is why, both primary and secondary sources were applied.

Upon the completion of sampled districts and VDCs, a survey questionnaire including required checklists was prepared. After the field preparation, the study team (principle investigator and field supervisors) moved to the respective headquarter of Kavre district where the team arranged a meeting of district level stakeholders (DHO, FPAN, and other health related organizations) for the appropriate selection of sample VDCs in the district. Same procedure was followed to other sample districts. Supervision and monitoring of the fieldwork were also managed. After editing the field data, they were analysed by using latest version of statistical program for social science (SPSS).
Ethical issue was also considered throughout the study period. After the approval of the tools and techniques for the fieldwork, the VDCs were selected with the help of the meetings of the respective stakeholders. Questionnaire was asked by visiting to the each sample Hh. The data were collected during leisure time of the informants. The privacy of each informant was considered.

\section{RESULTS}

The result has been discussed at two levels. At first, socio economic information has been analysed. And in second, focus will be given on the different issues of safe motherhood.

Sex is considered as the significant variable of the social, economic and demographic components. The present study reveals at first the distribution of the total population by sex/sex ratio and household size. The total population of the four sampled districts is found to be 2783 of which 1395 (50.1\%) are males and 1388 (49.8\%) are females. Of the total 2783 population, the highest number of population is in Saptari 1026 (36.8\%)followed by Dhanusa 767 (27.5\%), Kavre 571(20.5\%) and Lalitpur 419 (15\%). The overall sex ratio of the four sampled districts is 1.005 while the national sex ratio is slightly less i.e. 0.997 (CBS, 2001). If the sex ratio is compared among the sampled districts, it is the highest in Saptari (1.115) followed by Dhanusa (0.992), Lalitpur (0.976) and Kavre (0.866). Similarly, the overall Hh size is 6.95 for all the four districts, which is higher than national average Hh size 5.44(CBS 2001). It is happened by account of the majority sampled VDCs with rural background. However, the biggest Hh size (8.55) is in Saptari and the smallest (5.23) is in Lalitpur district (Table 1). The bigger Hh size indicates high fertility rate, low educational level and massive poverty and other encumbrances.

\begin{tabular}{|c|c|c|c|c|c|}
\hline \multirow{2}{*}{$\begin{array}{l}\text { Sex } \\
\text { Groups }\end{array}$} & \multicolumn{4}{|c|}{ Districts } & \multirow[b]{2}{*}{ Total } \\
\hline & Kavre & Lalitpur & Dhanusa & Saptari & \\
\hline \multirow{2}{*}{ Male } & 265 & 207 & 382 & 541 & 1395 \\
\hline & $46.40 \%$ & $49.40 \%$ & $49.80 \%$ & $52.72 \%$ & $50.12 \%$ \\
\hline \multirow{2}{*}{ Female } & 306 & 212 & 385 & 485 & 1388 \\
\hline & $53.59 \%$ & $50.59 \%$ & $50.19 \%$ & $47.27 \%$ & $49.87 \%$ \\
\hline \multirow{2}{*}{ Total } & 571 & 419 & 767 & 1026 & 2783 \\
\hline & $20.51 \%$ & $15.05 \%$ & $27.56 \%$ & $36.86 \%$ & $100 \%$ \\
\hline Sex Ratio & 0.866 & 0.976 & 0.992 & 1.115 & 1.005 \\
\hline Hh size & 7.13 & 5.23 & 6.39 & 8.55 & 6.95 \\
\hline
\end{tabular}

Source: Field survey, 2006 
Marital age plays a vital role in women health. Therefore, the team has garnered the information of marital age practicing in each sampled cluster. The table 2 indicates that $29 \%$ community people practice marriage below 18 years in total. Generally it is said that the women health can be weak if she marries below 18 years. If it is compared in sampled district, more than half respondents of both Terai districts like Dhanusa and Saptari marry below 18 years than other sampled districts. Being advanced area of the country, no marriage occurs below 18 years in Lalitpur district. Furthermore in Lalitpur, $46.3 \%$ reported practicing marital age in community is above 22 years influencing from urban area like Kathmandu.

Table 2. Marital Age Practicing in the Sample Districts

\begin{tabular}{|llllll|}
\hline & & \multicolumn{2}{c}{ Districts } & \multicolumn{2}{c}{ Total } \\
& Kavre & Lalitpur & Dhanusa & Saptari \\
\hline Below 13 & 2 & & 2 & 6 & 10 \\
yrs & $2.5 \%$ & & $1.7 \%$ & $5.0 \%$ & $2.5 \%$ \\
13 to 17 & 3 & & 48 & 56 & 107 \\
yrs & $3.8 \%$ & & $40.0 \%$ & $46.7 \%$ & $26.8 \%$ \\
18 to 22 & 65 & 43 & 68 & 57 & 233 \\
yrs & $81.3 \%$ & $53.8 \%$ & $56.7 \%$ & $47.5 \%$ & $58.3 \%$ \\
Above 22 & 10 & 37 & 2 & 1 & 50 \\
yrs & $12.5 \%$ & $46.3 \%$ & $1.7 \%$ & $.8 \%$ & $12.5 \%$ \\
Total & 80 & 80 & 120 & 120 & 400 \\
& $100.0 \%$ & $100.0 \%$ & $100.0 \%$ & $100.0 \%$ & $100.0 \%$ \\
\hline \hline
\end{tabular}

For improvement on maternal and child health, several steps related to safe motherhood have to be taken. During field visit, it was observed that pregnant women visited to ANC checked up. The study shows that of the total respondents in sample districts $87.5 \%$ have knowledge on ANC. If it is compared to district wise data, a higher proportion $(91.3 \%)$ has knowledge from Lalitpur followed by Dhanusa $(90.8 \%)$, Saptari $(86.7 \%)$ and Kavre (80\%). There are still $20 \%$ people in Kavre who do not know about the basic knowledge during pregnancy period (Table 3.).

Table 3. Knowledge of ANC

\begin{tabular}{|llllll|} 
& & \multicolumn{2}{c}{ Districts } & \multicolumn{2}{c|}{ Total } \\
& Kavre & Lalitpur & Dhanusa & Saptari \\
\hline Yes & 64 & 73 & 109 & 104 & 350 \\
& $80.0 \%$ & $91.3 \%$ & $90.8 \%$ & $86.7 \%$ & $87.5 \%$ \\
No & 16 & 7 & 11 & 16 & 50 \\
& $20.0 \%$ & $8.8 \%$ & $9.2 \%$ & $13.3 \%$ & $12.5 \%$ \\
Total & 80 & 80 & 120 & 120 & 400 \\
& $100.0 \%$ & $100.0 \%$ & $100.0 \%$ & $100.0 \%$ & $100.0 \%$ \\
\hline \hline
\end{tabular}

Out of the total 394 respondents with child have also asked on the place of recent delivery. Of the total respondent, overwhelmingly majority (80.5\%) has practiced home delivery followed by public health institute $(18.3 \%)$ and private clinic/ nursing home (1.3\%). If it is compared on district wise data in case of home delivery, majority $(89.9 \%)$ is from Saptari followed by Kavre $(86.1 \%)$ and Dhanusa (85.8\%). However around $50 \%$ reported home delivery in Lalitpur district. Such practice is comparatively found less in this district by account of sampled VDC situated nearby capital city, Kathmandu (Table 4).

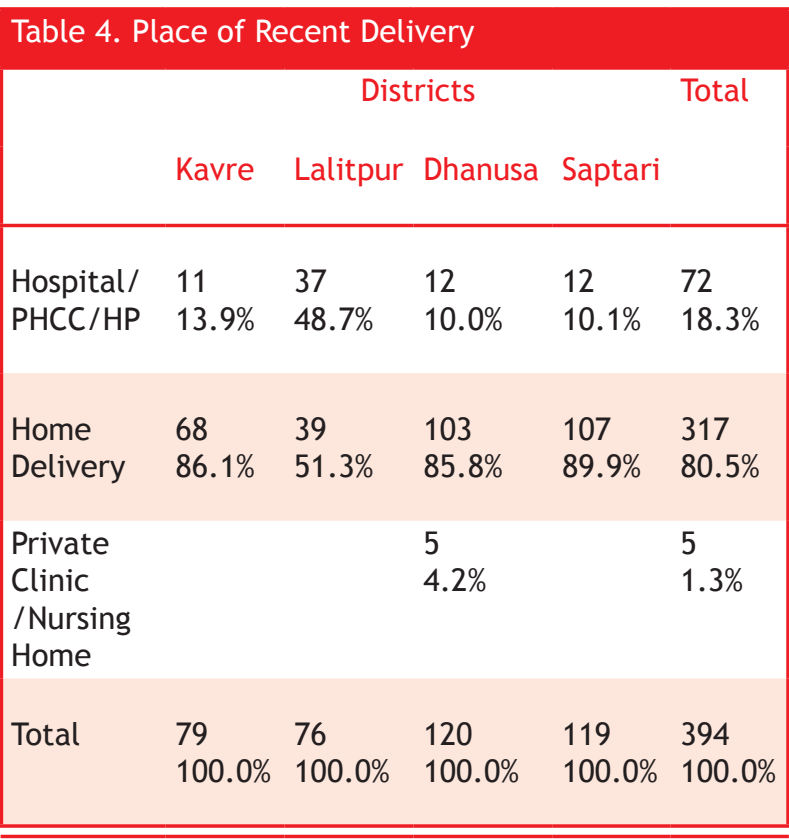

Being 6 respondents without child, the total number in 394.

During fieldwork, posters, leaflet and brochure related to safe motherhood were also observed. Calendar would be also more useful materials either for day-today activities or learning more about safe motherhood. With the help of such materials, the awareness level in sampled VDCs has been found gradually improving.

Being the multiple choices, the total respondents are calculated 616 on this issue (Table 5). Out of the total respondents, majority (33\%) reported health workers as an important source followed by mother in law (30\%), TBA (25.8\%) and others including neighbors, sister, and sister in law (10.7\%). If it is compared in sampled districts on mother in law as source of knowledge, a higher majority $(50.4 \%)$ is in Kavre followed by Dhanusa (30.6\%), Saptari (23.6\%) and Lalitpur (18.9\%). 
Public Health Awareness Building in the field of Safe Motherhood

\begin{tabular}{|llllll|}
\hline \multicolumn{5}{|c|}{ Table 5. Assistants During Delivery } & \multicolumn{2}{c|}{ Total } \\
\multicolumn{5}{c}{ Districts } \\
& Kavre & Lalitpur & Dhanusa & Saptari \\
\hline Health & 26 & 70 & 62 & 48 & 206 \\
Workers & $23.4 \%$ & $53.0 \%$ & $27.5 \%$ & $32.4 \%$ & $33.4 \%$ \\
Mother in & 56 & 25 & 69 & 35 & 185 \\
law & $50.4 \%$ & $18.9 \%$ & $30.6 \%$ & $23.6 \%$ & $30 \%$ \\
TBA & 10 & 25 & 76 & 48 & 159 \\
& $9 \%$ & $18.9 \%$ & $33.7 \%$ & $32.4 \%$ & $25.8 \%$ \\
Others & 19 & 12 & 18 & 17 & 66 \\
& $17.7 \%$ & $9 \%$ & $8 \%$ & $11.4 \%$ & $10.7 \%$ \\
Total & 111 & 132 & 225 & 148 & 616 \\
& $100 \%$ & $100 \%$ & $100 \%$ & $100 \%$ & $100 \%$ \\
\hline \hline
\end{tabular}

Being multiple responses, the total numbers exceed.

During delivery period, it should be carefully managed of the instruments for cutting placenta. The table 6 indicates that majority of recipients (58.9\%) are found to use blades followed by sterilized blades (26.1\%) and other including sickle and knife (15\%). From the district wise comparison, it is found that majority of respondent from Saptari $(71.4 \%)$ use blade followed by Lalitpur (59.2\%), Dhanusa (57.5\%) and Kavre (41.8\%).

\begin{tabular}{|llllll|}
\hline \multicolumn{5}{|c|}{ Table 6. Instrument for Cutting Placenta } \\
& Kavtricts & & & \multicolumn{3}{l|}{ Total } \\
& Kavre & Lalitpur & Dhanusa & Saptari \\
\hline Blade & 33 & 45 & 69 & 85 & 232 \\
& $41.8 \%$ & $59.2 \%$ & $57.5 \%$ & $71.4 \%$ & $58.9 \%$ \\
Sterilized & 8 & 28 & 50 & 17 & 103 \\
blade & $10.1 \%$ & $36.8 \%$ & $41.7 \%$ & $14.3 \%$ & $26.1 \%$ \\
Others & 38 & 3 & 1 & 17 & 59 \\
& $48.1 \%$ & $3.9 \%$ & $.8 \%$ & $14.3 \%$ & $15.0 \%$ \\
Total & 79 & 76 & 120 & 119 & 394 \\
& $100.0 \%$ & $100.0 \%$ & $100.0 \%$ & $100.0 \%$ & $100.0 \%$ \\
\hline \hline
\end{tabular}

Colostrums to infant is very essential for the healthy and growth. The field data has revealed that majority of the respondents $(69 \%)$ reported they practice colostrums to infant. If it is compared in sample district, a higher proportion of Kavre (84.8\%) practice colostrums followed by Lalitpur (81.6\%), Dhanusa (61.7\%) and Saptari (58\%). In ecological belt, majority of respondents of hilly sampled districts have practiced than Terai sampled districts (Table 7).

\begin{tabular}{|c|c|c|c|c|c|}
\hline & \multicolumn{4}{|c|}{ Districts } & \multirow[t]{2}{*}{ Total } \\
\hline & Kavre & Lalitpur & Dhanusa & Saptari & \\
\hline \multirow[t]{2}{*}{ Yes } & 67 & 62 & 74 & 69 & 272 \\
\hline & $84.8 \%$ & $81.6 \%$ & $61.7 \%$ & $58.0 \%$ & $69.0 \%$ \\
\hline \multirow[t]{2}{*}{ No } & 12 & 14 & 46 & 50 & 122 \\
\hline & $15.2 \%$ & $18.4 \%$ & $38.3 \%$ & $42.0 \%$ & $31.0 \%$ \\
\hline \multirow[t]{2}{*}{ Total } & 79 & 76 & 120 & 119 & 394 \\
\hline & $100.0 \%$ & $100.0 \%$ & $100.0 \%$ & $100.0 \%$ & $100.0 \%$ \\
\hline
\end{tabular}

During fieldwork, it was found that the uterus prolapse is in critical in the sampled districts. Most the female respondents argued maternal health has been more affected by such disease. Furthermore, they suggested that uterus prolapse has to be examined by organizing health camp in distant area. In Ballakathal VDC of Dhanusa district, a critical case was encountered that a Kurmi woman sent her husband to the field study team where they were in night camp for hearing her problem and getting the way to be free from such disease. In reality, it is hidden problem because the patient takes regular food and performs other activities properly. The family members do not easily trust she has a problem. Therefore, such type of hidden case cannot be exposed until the affected person bring into a continue illness or completely bed rest.

\section{DISCUSSION}

Safe motherhood is also one of the important components of sexual and reproductive health. There are various components related to the safe motherhood. Efforts will be given discussing them respectively. Maternal health can be affected by marital age. In totality in the sampled districts of this study, $29 \%$ community people were found marital aged below 18 years. In health perspective, it is said that the women health could be weak if she married below 18 years age. Therefore, government of Nepal has made the act for not marrying below the age of 18 years. Furthermore, the study reveals a high proportion (58.37) married at the age of 18 to 22 years. The results nearly coincide with FPAN. According to FPAN (2005), $54.7 \%$ repondents were found marrying at $15-19$ years of age. Many pregnant are generally found suffering at the time of delivery because of the lack of proper knowledge on reproductive and sexual health, place of delivery, assistance during pregnancy, available health facilities and so forth. The present study shows that a high majority (80.5\%) were found home delivery in four sampled districts. The finding was exactly supported with same FPAN result. ${ }^{8}$ The present study also indicates that of the total respondents, most of them (87.5\%) have clear knowledge about ante- natal care (ANC). This result is contradicted with DoHS. DoHS found different 
results in the gap of the different fiscal years. During fiscal year 2001/02, $42.7 \%$ of the expected pregnant mother received ANC services at least for one time, 53.1\% during 2002/03 and $66.1 \%$ during 2003/04. ${ }^{2}$

Among the different factors of safe motherhood, it should be considered on the place of delivery. The present study has demonstrated majority of the respondents (33\%) reported health workers are the prime source for the assistance during delivery. Furthermore, the same study added that $30 \%$ mothers in law have assisted to the pregnant for safe delivery. However, DoHS has quite contradicted result. The health workers (18.3\%) assisted mothers for delivery during the fiscal year 2003/04. ${ }^{2}$ During delivery period, it should be carefully managed of the instruments for cutting placenta. The field data of the present study indicates that majority of recipients (58.9\%) are found to use blades followed by sterilized blades (26.1\%) and others (15\%).

During fieldwork, posters, leaflets and brochures related to safe motherhood were also observed. With the help of such materials, the awareness level in sampled VDCs has been found gradually increasing. NHEICC has found some specific results in this regard. Of the179 respondents exposed to the posters of safe motherhood, 93\% reported having learned from the posters. Proportion of respondents learning from posters was found highest in Terai $(95.4 \%)$ followed by hills $(92.6 \%)$ and mountains $(90.9 \%){ }^{9}$

Breast milk contains all types of nutrients required for a child in right proportion with quality as well as good composition. Furthermore, the initiation of first breast milk is very important for the babies because it contains colostrums. ${ }^{10}$ In the field of maternal and child health, colostrums is very useful nutrient to infants for their health and growth. Proper use of colostrums helps both child and maternal health. Sometime, it is also found some mothers might be affected due to the improper use of first breast milk. The present study reveals 69\% respondents practised first breast milk to infants. In Kavre district only, $84.8 \%$ practised colostrums to infant.

In this study, it was also observed that uterus prolapse has created complexity on maternal health. Most of the female respondents of the sampled VDCs expressed that uterus prolapse has to be examined by organizing health camp in distant area. In this sense, most of the women in remote area have to be aware on the critical situation like such problem at the one side and government and NGO have to be organised regular mobile clinic or health camp prioritised to maternal health in the country.

\section{CONCLUSION}

Safe motherhood is the significant component of reproductive health. Majority people still practised delivery at home rather than public health institutes. The study indicates that $80.5 \%$ population reported they managed home delivery followed by health institutes (18.3\%). Similarly, 30\% respondents expressed mothersin-law assist during delivery. 69\% informants reported that they milked colostrums to infant. Despite some positive achievements in this field, some areas are still found weak and critical. Hence, it is suggested that the government and NGOs have arranged awareness campaigns focusing to the critical area of the problems.

\section{ACKNOWLEDGE}

The author would like to thank to NHRC for supporting during fieldwork. I also thank to the field supervisors accompanied myself for their assistance in the course of the field visit. I am extremely grateful to all the respondents for their kind cooperation during data collection to my team and myself.

\section{REFERENCE}

1. Central Bureau of Statistics. Population Census. Kathmandu: 2001.

2. Department of Health Service. Annual Report 2003/4. Kathmandu: 2003.

3. Nepal Family Health Project. Nepal Family Health Survey. Kathmandu: 1996

4. Ministry of Agriculture and Cooperatives. Annual Journal. Kathmandu: 2061

5. A framework of health education, information and communication program in Nepal. Journal of NHEICC 2062;2-34

6. Park K. Preventive and Social Medicine. Jabalpur (India): M/s Banarsidas Bhanot Publishers; 2005. p. 12 -8.

7. Nepal Health Research Council. Final Report on IEC/BCC Programs and their impacts on knowledge and behavior of people of Nepal. Kathmandu: Nepal Health Research Council; 2007. p. 42 .

8. Family Planning Association of Nepal. Final report of the baseline survey on sexual and reproductive health knowledge, attitude, behavior and practice among adolescent, youth and adult people in FPAN operational area. Kathmandu: 2005

9. NHEICC. An evaluation study of national health education, information and communication program. Kathmandu: NHEICC; 2003. p. 63-65.

10. Aryal TR. Differentials of breast feeding among rural women of western Nepal: A survival analysis. JNHRC. 2005;58:5. 